\title{
ПРАВО
}

LAW

УДК 347.795

https://doi.org/10.24866/1813-3274/2021-2/88-97
А. Ю. Чурилов ${ }^{1}$, Томский государственный университет систем управления и радиоэлектроники, г. Томск, Россия
E-mail: Lefikantor@yandex.ru
ORCID ID: 0000-0001-9435-1626

\section{КЛАССИФИКАЦИЯ КОНОСАМЕНТОВ И ЕЁ ПРАВОВОЕ ЗНАЧЕНИЕ}

История развития коносамента - от расписки в получении груза до товарораспорядительного документа и применения его в обороте - достаточно длительна, и его эволюция, а также постоянно растущие потребности рынка породили множество разновидностей коносамента. В работе рассматриваются классификации коносаментов по различным критериям, а также правовое значение этих классификаций. Автор демонстрирует разницу между береговым и бортовым коносаментом; чистым коносаментом и коносаментом с оговорками; и другими разновидностями. В работе освещены отдельные особенности различных режимов регулирования коносаментов, закреплённых в трёх международных конвенциях. Целью исследования является необходимость систематизации существующих коносаментов и освещение того, как их разновидности могут влиять на отношения сторон.

Ключевые слова: коносамент, договор перевозки, товарораспорядительный документ, ценная бумага, третье лицо, аккредитив, договор морской перевозки, прямое смешанное сообщение, классификация, передача коносамента, чистый коносамент, функции коносамента.

\footnotetext{
${ }^{1}$ Алексей Юрьевич Чурилов, кандидат юридических наук, доцент кафедры гражданского права Юридического факультета, Томский государственный университет систем управления и радиоэлектроники, г. Томск, Россия.

Для циттирования: Чурилов А. Ю. Классификация коносаментов и её правовое значение // АзиатскоТихоокеанский регион: экономика, политика, право. 2021. № 2. C. 88-97. DOI https://doi.org/10.24866/1813-3274/2021-2/88-97.

(C) Чурилов А. Ю., 2021
} 

A. Yu. Churilov ${ }^{1}$, Tomsk State University of Control Systems
and Radioelectronics, Tomsk, Russia
E-mail: Lefikantor@yandex.ru
ORCID ID: 0000-0001-9435-1626

\section{CLASSIFICATION OF BILLS OF LADING AND THEIR LEGAL MEANING}

The history of the development of the bill of lading - from the receipt of the cargo to the document of title and its use in circulation - is quite long, and its evolution, as well as the constantly growing market needs, gave rise to many varieties of the bill of lading. The work examines the classification of bills of lading according to various criteria, and the legal significance of these classifications. The author shows the difference between an onshore and an onboard bill of lading; clean bills of lading and qualified bill of lading; and other varieties. The work highlights some specific features of various regimes of regulation of bills of lading, enshrined in three international conventions. The aim of the study is to systematize the existing bills of lading and highlight how their varieties affect the relationship of the parties.

Keywords: bill of lading, contract of carriage, the document of title, security, third party, letter of credit, contract of carriage by sea, multimodal shipping, classification, endorsement of bill of lading, clean bill of lading, functions of bill of lading.

Коносамент - это ценная бумага, представляющая собой товарораспорядительный документ, подтверждающий факт заключения договора перевозки груза и принятия груза перевозчиком, удостоверяющий право его держателя распоряжаться указанным в коносаменте грузом, сданным для морской перевозки, и получить этот груз после завершения перевозки. Первые прообразы коносамента можно найти еще в Римском частном праве, однако в то время он выполнял лишь функцию расписки в получении товара на борт судна [6].

Изначально, как отмечали английские суды, коносамент представлял собой лишь расписку в получении груза перевозчиком ${ }^{2}$, и только в конце XVIII в. стал признаваться товарораспорядительным документом и содержать в себе условия договора перевозки³. В настоящее время существует несколько правовых режимов,

\footnotetext{
${ }^{1}$ Aleksei Yuryevich Churilov, Judicial Science Candidate, Assistant professor, Department of Civil Law, law Faculty, Tomsk State University of Control Systems and Radioelectronics, Tomsk, Russia.

For citing: Churilov A. Yu. Classification of bills of lading and its legal meaning // Pacific RIM: Economics, Politics, Law. 2021. No. 2. P. 88-97. DOI https://doi.org/10.24866/1813-3274/2021-2/88-97.

${ }^{2}$ Sewell v. Burdick (1884). 10 AC 74.

${ }^{3}$ Lickbarrow v. Mason. (1787) 2 TR 63, 100 ER 35.
} 
регулирующих морские перевозки грузов, и требования, предъявляемые к коносаментам. Эти режимы закреплены в таких международных договорах, как Международная конвенция об унификации некоторых правил о коносаменте 1924 г. ${ }^{\text {; }}$ Протокол об изменении Международной конвенции об унификации некоторых правил о коносаменте от 25 августа 1924 г., измененной Протоколом от 23 февраля 1968 г. (Подписан в г. Брюсселе 21.12.1979)²; Конвенция ООН «О морской перевозке грузов» 1978 г. ${ }^{3}$; Конвенция ООН «О договорах полностью или частично морской международной перевозки грузов» 2008 г. ${ }^{4}$ [2]. Следует подчеркнуть, что из перечисленных международных договоров Россия участвует только в первых двух.

В современном морском товарообороте коносамент выполняет три функции - является способом передачи владения товаром (товарораспорядительной ценной бумагой), распиской в принятии груза перевозчиком и доказательством заключения договора перевозки (а также может содержать отдельные условия договора перевозки) [5].

Длительная история существования и эволюции коносамента, а также потребности рынка обусловили возникновение множества его разновидностей, которые можно объединить в несколько групп по различным классификационным критериям.

В зависимости от места нахождения груза выделяют береговой и бортовой коносаменты. Следует отметить, что коносамент, по общему правилу, является именно распиской в получении груза перевозчиком, но не распиской в погрузке на борт. Это следует как из норм отечественного (ст. 144 КТМ РФ), так и международного законодательства (ст. 14-16 Гамбургских правил, статья 3 Правил Висби), в соответствии с которыми, когда перевозчик или фактический перевозчик принимает груз в своё ведение, перевозчик по требованию грузоотправителя обязан выдать грузоотправителю коносамент. И только после того, как груз погружен на борт, перевозчик, если того потребует грузоотправитель, должен выдать грузоотправителю бортовой коносамент (коносамент с бортовой пометкой), в котором должно быть указано, что груз находится на борту определённого судна или судов, а также должна быть указана дата или даты погрузки. Гамбургские правила прямо закрепляют то, что коносамент является доказательством prima facie приёма, а в случае выдачи бортового коносамента - погрузки перевозчиком груза, как он описан в коносаменте.

Классификация коносамента на береговой и бортовой имеет важное значение при расчётах аккредитивами - если стороны условились, что оплата будет произведена при погрузке товара на борт судна, то береговой коносамент не будет являться основанием для осуществления банком оплаты, поскольку не были представлены необходимые документы. К примеру, если стороны заключили договор междуна-

\footnotetext{
${ }^{1}$ Гаагские правила.

2 Правила Висби.

${ }^{3}$ Гамбургские правила.

${ }^{4}$ Роттердамские правила.
} 
родной купли-продажи, например, на условиях FCA ИНКОТЕРМС 2020, с возложением на продавца обязанности получения транспортного документа - коносамента - и с условием об оплате по правилам Унифицированных обычаев по оплате аккредитивами ${ }^{1}$ с момента отправки товара. В соответствии с этими правилами (статья 20) коносамент должен указывать, что товар был погружен на борт названного судна в порту погрузки, указанном в аккредитиве, в виде заранее напечатанного в бланке текста или бортовой пометки с указанием даты погрузки товара на борт. При этом, если коносамент содержит указание на «предполагаемое судно» или подобное ему в отношении названия судна, то требуется проставление на нём бортовой пометки с указанием даты отгрузки и названия судна, на которое фактически был отгружен товар. Таким образом, предоставление в банк берегового коносамента не будет являться надлежащим документом для получения оплаты.

В зависимости от способа передачи коносамент, как и любая ценная бумага, может быть предъявительским, ордерным и именным. Следовательно, коносамент может быть выдан на имя определённого получателя (именной коносамент), приказу отправителя или получателя (ордерный) либо на предъявителя (предъявительский).

Именной коносамент является так называемой ректа-бумагой, под которой понимается ценная бумага, которая легитимирует своего держателя, если он назван в качестве управомоченного в тексте предъявленной им бумаги или признается его правопреемником на основании общих норм гражданского права [4]. Именной коносамент содержит безотзывную инструкцию перевозчику о получателе груза, по этой причине оборотным быть не может [1]. При этом вопрос о том, является ли именной коносамент товарораспорядительным документом, особенно в контексте применения к отношениям сторон правил Висби, до сих пор остается открытым, и ответ на него зависит не в последнюю очередь от содержания коносамента и его условий. К примеру, в одном из дел английский суд признал именной коносамент товарораспорядительным документом в том числе на том основании, что условия, содержащиеся на его оборотной стороне, недвусмысленно требовали его предъявления для получения груза ${ }^{2}$ С такой позицией следует согласиться, поскольку в том случае, если стороны хотят получить необоротный транспортный документ то им следует воспользоваться общепризнанными конструкциями, например, необоротной морской накладной.

С точки зрения функций и природы коносамента выделяют чартерный коносамент или коносамент, выданный в отсутствии чартера. Общепризнанно, что коносамент, хотя и содержит многие условия договора, тем не менее является доказательством его заключения, не являясь при этом самим договором перевозки. Дей-

\footnotetext{
${ }^{1}$ Унифицированные правила и обычаи для документарных аккредитивов (UCP 600). Редакция 2007 г. Публикация Международной торговой палаты № 600.

2 JI MacWilliam Company Inc v. Mediterranean Shipping Company SA. [2005] UKHL 11.
} 
ствительно, анализ норм, регулирующих морскую перевозку, позволяет прийти к выводу, что коносамент является именно подтверждением заключения договора перевозки (ст. 117 КТМ РФ, ст. 1 Правил Висби, ст. 1 Гамбургских правил).

В случае выдачи чартерного коносамента ситуация совершенно иная. По общему правилу, такой коносамент не обладает товарораспорядительными функциями и является лишь распиской в принятии груза перевозчиком. Однако, в соответствии со ст. 119 КТМ РФ, отношения между перевозчиком и не являющимся стороной договора морской перевозки груза получателем определяются коносаментом. Международные акты также устанавливают сходные правила. Так, в соответствии с Правилами Висби, термин «договор перевозки» применяется исключительно к договору перевозки, удостоверенному коносаментом или любым подобным ему документом, являющимся основанием для морской перевозки грузов. Однако он применяется также к коносаменту или подобному ему документу, выданному на основании чартера, с того момента, когда такой коносамент или документ регулирует отношения между перевозчиком и держателем этого коносамента или документа. Такие же правила содержатся в Гамбургских правилах, в соответствии с которыми, когда коносамент выдаётся согласно чартеру, положения Конвенции применяются к такому коносаменту, если он регулирует отношения между перевозчиком и держателем коносамента, не являющимся фрахтователем.

При этом следует исходить из того, что договор между владельцем коносамента и грузоперевозчика считается, по общему правилу, существующим на условиях, закреплённых в коносаменте ${ }^{1}$. Если речь идет о коносаменте, выданном на основании чартера, к примеру, в соответствии с нормами отечественного законодательства, условия чартера обязательны для получателя, если коносамент содержит ссылку на них. При этом применяться должны те условия чартера, которые были согласованы на момент передачи коносамента третьему лицу ${ }^{2}$ Это правило имеет существенное значение в случае задержки груза или его повреждения, особенно если в договоре перевозки содержится указание на ограничение ответственности перевозчика, которое не содержится в коносаменте. Так, в одном из дел, рассмотренных в Англии, суд применил положения не договора перевозки, но положения коносамента как «если бы индоссату были переданы права по договору, условия которого закреплены в коносаменте»³.

\footnotetext{
${ }^{1}$ Такой позиции придерживаются как английские (Brandt v Liverpool, Brazil \& River Plate Steam Navigation Co Ltd [1924] 1 KB 575), так и европейские (Coreck Maritime (Judgments Convention/Enforcement of judgments) [2000] EUECJ C-387/98) суды.

2 Tradigrain SA \& Ors v King Diamond Marine Ltd «The Spiros C» [2000] EWCA Civ 217.

${ }^{3}$ Leduc v Ward [1893] A. C. 351. Существует и прямо противоположное мнение, в соответствии с которым коносамент не превращается в договор, а речь идет всё же о договорном эстоппеле. - См. Sewell v Burdick. [1884] 10 AC 74.
} 
Кроме того, в случае возникновения споров относительно доставки груза, его сохранности и т. д., ответчиком в таком споре может являться не судовладелец (как это происходит по общему правилу), представитель которого - капитан - выдает такой коносамент, а сторона чартера (фрахтователь), выдавшая коносамент. Такое правило действует в том случае, если из отношений сторон следует явное намерение связь обязательствами именно фрахтователя и держателя коносамента - к примеру, в том случае, если представитель фрахтователя выдаст коносамент с подписью поверх отметки «подпись капитана» ${ }^{1}$. Также условиями чартера может быть предусмотрено, что даже в том случае, если капитан выдаст отправителю коносамент, он не будет порождать права и обязанности для судовладельца ${ }^{2}$. Вместе с тем, даже в том случае, если ответственным по чартерному коносаменту является судовладелец, многие проформы чартеров, к примеру, Baltime, содержат оговорку об индемнитете, т. е. об обязанности возмещения потерь, возникших в случае наступления определённых в договоре обстоятельств, - в настоящее время как зарубежное, так и с 2015 г. отечественное законодательство (ст. 406.1 ГК РФ) позволяют включать такую оговорку в договор.

Таким образом, только коносамент, являющийся единственным перевозочным документом, или чартерный коносамент, переданный третьему лицу, приобретают самостоятельное вещно-обязательственное значение в обороте.

С рассмотренной классификацией тесно связана следующая. $B$ зависимости от субъекта вылачи можно выделять коносамент судовладельца или коносамент фрахтователя.

В зависимости от состояния погруженного на борт судна товара или полученного перевозчиком выделяют «чистый» коносамент и коносамент с оговорками. Если внешнее состояние груза не отражено в коносаменте, то презюмируется «хорошее» состояние груза - коносамент без отметок о повреждениях товара называется «чистым» коносаментом. Если в коносаменте будет указано на хорошее состояние груза в отсутствие такового, то перевозчик не сможет ссылаться на то, что груз был поврежден, особенно в спорах с грузополучателем - третьим лицом, в силу как прямого указания закона, так и в силу действия принципа эстоппель, если речь идёт о странах общего права. То есть коносамент является опровержимой презумпцией (в отсутствие соответствующих оговорок в нём) качества, количества и состояния груза. При этом, в соответствии с общепринятыми нормами, опровержение этой презумпции не допускается, если коносамент передан третьему лицу, которое, исходя из содержащегося в коносаменте описания груза, действовало добросовестно (ст. 16 Гамбургских правил, ст. 3 Правил Висби, ст. 145 КТМ РФ).

\footnotetext{
${ }^{1}$ The Okehampton. [1913] P. 173.

${ }^{2}$ Manchester Trust v Furness. [1895] 2 QB 539.
} 
В том случае, если по «чистому» коносаменту прибыл повреждённый груз, то ответственность за его состояние несёт перевозчик - поэтому надлежащее исследование груза является важнейшим правом судовладельца. В этой связи ни перевозчик, ни капитан, ни агент перевозчика не обязан объявлять или указывать в коносаменте марки, число мест, количество или вес, которые, как он имеет серьёзное основание подозревать, не точно соответствуют грузу, в действительности принятому им, или которые он не имеет возможности проверить разумными средствами.

Вместе с тем, в некоторых случаях представитель судовладельца может выдать чистый коносамент без надлежащего исследования груза на основе заверений отправителя груза. В таком случае, в отсутствие недобросовестности действий самого перевозчика ${ }^{1}$, действует установленное Правилами Висби (п. 5 ст. 3) положение, в соответствии с которым считается, что отправитель гарантировал перевозчику на момент погрузки точность марок, числа мест, количества и веса груза, как они им указаны, и отправитель обязан возместить перевозчику все потери, убытки и расходы, возникшие вследствие или явившиеся результатом неточности этих данных. Право перевозчика на такое возмещение никоим образом не ограничивает его ответственность и его обязанности по договору перевозки перед любым лицом, иным чем отправитель. В данном случае речь идёт о индемнитете в силу закона. Такая презумпция согласуется и с общими положениями ст. 10 ГК РФ - как отмечается в отечественной судебной практике, добросовестность и разумность действий сторон предполагаются и, соответственно, при нормальном течении товарооборота не имелось серьёзных оснований подозревать, что с грузом и документами что-то не в порядке и основания для снятия пломб, вскрытия контейнера и взвешивания груза не имелись ${ }^{2}$. Однако следует отметить, что в отношении состояния груза этот индемнитет не действует.

Особое значение имеет «чистота» коносамента при использовании расчетов аккредитивами. Так, по общему правилу, банки будут принимать только чистый транспортный документ как надлежащий для выплаты по аккредитиву.

В зависимости от процедуры перевозки груза выделяются три вида коносаментов:

Прямой коносамент (Direct Bill of Lading) - коносамент, покрывающий отгрузку между непосредственными портами погрузки и выгрузки на одном и том же судне.

Сквозной коносамент (Through Bill of Lading) - коносамент, предусматривающий перевалку груза на другое судно в промежуточном пункте и покрывающий всю перевозку груза от порта погрузки до места конечного назначения. В соответствии со сложившимися международными правилами коносамент может указы-

\footnotetext{
${ }^{1}$ См., например, Standard Chartered Bank v Pakistan National Shipping Corp. [2002] UKHL 43.

${ }^{2}$ Решение Санкт-Петербургского городского суда от 12.08.2014 № 12-1350/2014 по делу № 5-792/2014
} 
вать, что товар будет или может быть перегружен при условии, что вся перевозка покрывается одним и тем же коносаментом.

Мультимодальный (смешанный) коносамент (Combined Transport Bill of Lading) - коносамент, который выдается в том случае, если груз доставляется несколькими видами транспорта. Перегрузка в таком случае означает выгрузку с одного транспортного средства и последующую погрузку на другое транспортное средство (того же или другого вида транспорта) в процессе перевозки из места отправки, принятия к перевозке или отгрузки в место конечного назначения. В отличие от прямого и сквозного коносамента, сложно утверждать, что мультимодальный коносамент будет являться товарораспорядительным документом, поскольку не вполне соответствует требованиям, предъявляемым к реквизитам коносамента, так как не вся транспортировка будет осуществляться посредством морского транспорта. Вместо такого коносамента, в соответствии с правилами ЮНКТАД/ІСС может быть выдан «документ смешанной перевозки» (multimodal transport document), который является оборотным товарораспорядительным документом ${ }^{1}$. Схожие положения содержатся и в не вступившей в силу Конвенции Организации Объединенных Наций о международных смешанных перевозках грузов 1980 г. Транспортный документ, указывающий, что перегрузка будет или может иметь место, является приемлемым при расчёте аккредитивами.

В зависимости от перевозчика выделяют:

Линейный, или рейсовый, коносамент (Liner bill of lading), выдаваемый судоходной компанией или от её имени и покрывающий перевозку на судах, курсирующих по регулярным маршрутам в соответствии с установленным и опубликованным расписанием [3]. Также по условиям такого договора перевозки перевозчик обязан осуществить погрузку, укладку и разгрузку товара.

Океанический коносамент (Ocean bill of lading), выдаваемый в том случае, если происходит перевозка груза на специально выбранном для этого транспорте через океан/море, как правило, за пределы страны отправки. Договор перевозки вступает в силу с момента погрузки товара на борт судна и прекращает свое действие в момент разгрузки судна.

В зависимости от объёма прав держателя коносамента существуют действующий и «погашенный» (spent) коносамент - который не может выполнять товарораспорядительную функцию, поскольку в связи с тем, что груза больше нет у перевозчика. Очевидно, что товарораспорядительная ценная бумага может существовать только при наличии соответствующего обязательства и прекращает своё существование при его прекращении. Наиболее тривиальный случай, когда коносамент становится погашенным, - когда в обмен на него выдается груз. Однако на практи-

\footnotetext{
${ }^{1}$ См.: Правила ЮНКТАД/ІСС для документов смешанных перевозок. ICC Publication № 481.
} 
ке возникают и боле противоречивые ситуации - например, если перевозчик выдал груз уполномоченному на то получателю ${ }^{1}$ в отсутствие у последнего коносамента либо в результате нескольких сделок погашенный коносамент оказался в руках банка. Наличие различных заверений или обязательств по индемнитету на стороне даже уполномоченного грузополучателя не влияет на квалификацию действий перевозчика как ненадлежащего исполнения обязательства, поскольку он обязан выдать груз только при предъявлении оригинала коносамента ${ }^{2}$. Погашенный коносамент, с учётом отсутствия у перевозчика груза, даёт владельцу лишь право требования возмещения соответствующих убытков, связанных с нарушением перевозчиком обязательства из договора перевозки, но только лишь в том случае, если договоренности о передаче коносамента держателю были достигнуты до момента погашения коносамента ${ }^{3}$.

Подводя итог, следует заключить, что долгая история существования коносамента породила множество различных его классификаций, имеющих значение как для оплаты товара, так и для определения лица, ответственного перед грузополучателем или законным владельцем коносамента за ненадлежащее исполнения обязательства.

\section{Список литературы}

1. Голубчик, А. М. О некоторых аспектах возможности применения электронного коносамента в практике нефтетрейдеров / А. М. Голубчик, П. Б. Катюха // Российский внешнеэкономический вестник. - 2017. - № 4. - С. 97-106.

2. Иванова, Т. А. Международные морские перевозки грузов: правовое регулирование // Международное публичное и частное право. - 2018. - № 5. - С. 14-16.

3. Макарова, Н. В. Коносамент в международных морских перевозках // Международные банковские операции. - 2009. - № 4. - С. 55-64.

4. Чуваков, В.Б. Правовая природа ректа-бумаг // Законы России: опыт, анализ, практика. - 2006. - № 7. - С. 19-24.

5. Чурилов, А. Ю. К вопросу о правовой природе и функциях коносамента // Законодательство. - 2020. - № 10. - С. 25-31.

6. Du Toit, S. F. The evolution of the bill of lading // Fundamina: A Journal of Legal History. - 2005. - № 11. - P. 12-25.

\footnotetext{
${ }^{1} \mathrm{O}$ том, что коносамент не становится «погашенным» в случае выдачи груза не уполномоченному получателю, отмечено во многих делах, рассматриваемых английскими судами. Обзор части из них можно увидеть в деле East West Corporation v DKBS 1912 \& Anor [2002] EWHC 83 (Comm).

${ }^{2}$ См., в частности, Standard Chartered Bank v Dorchester Lng (2) Ltd Re: MT ERIN SCHULTE [2013] EWHC 808 (Comm).

${ }^{3}$ Речь идёт именно о договорённости, но не о фактической передаче. См., в частности: The Delfini. [1990] 1 Lloyd's 252.
} 


\section{References}

1. Golubchik A. M., Katyuha P. B. O nekotorykh aspektakh vozmozhnosti primeneniya elektronnogo konosamenta $\mathrm{v}$ praktike neftetreiderov [On some aspects of the possibility of using an electronic bill of lading in the practice of oil traders]. Rossiiskii vneshneekonomicheskii vestnik, 2017, no. 4, pp. 97-106.

2. Ivanova T. A. Mezhdunarodnye morskie perevozki gruzov: pravovoe regulirovanie [International sea transportation of goods: legal regulation]. Mezhdunarodnoe publichnoe i chastnoe pravo, 2018, no. 5, pp. 14-16.

3. Makarova N. V. Konosament $\mathrm{v}$ mezhdunarodnykh morskikh perevozkakh [Bill of lading in international shipping]. Mezhdunarodnye bankovskie operatsii, 2009, no. 4, pp. 55-64.

4. Chuvakov V. B. Pravovaya priroda rekta-bumag [The legal nature of rect-paper]. Zakony Rossii: opyt, analiz, praktika, 2006, no. 7, pp. 19-24.

5. Churilov A. U. K voprosu o pravovoi prirode i funktsiyakh konosamenta [On the question of the legal nature and functions of the bill of lading]. Zakonodatel'stvo, 2020, no. 10 , pp. $25-31$.

6. Du Toit S. F. The evolution of the bill of lading. Fundamina: A Journal of Legal History, 2005, no. 11, pp. 12-25. 